\title{
A Study Of Entrepreneurial Intentions Among Business and Commerce Graduates: Evidence From Public Sector Universities of Sindh
}

\author{
Dr. Sadia Anwer \\ Institute of Commerce, University of Sindh, Jamshoro \\ Dr. Javed Ahmed Chandio \\ Institute of Commerce, University of Sindh, Jamshoro
}

Muhammad Ashraf

Faculty of Management Sciences, Shah Abdul Latif University, Khairpur

\begin{abstract}
Developing nations, like Pakistan, have been espousing a host of several economic challenges. Finding a job for an educated person is hard. The governments of these nations are struggling with the scarcity of resources to accommodate the young human capital. Hence under such perplexing conditions, the finding and earning a source of bread and butter under the name of entrepreneurship has been considered as the best solution to the challenge. However, being an entrepreneur in a country like Pakistan requires several cool capabilities and attitudes. The educational pattern in Pakistan is shaping the youngsters to meet the challenges of the job market, by replacing them with an entrepreneurial attitude. This study is, therefore, has attempted to investigate the relationship between business and commerce graduates' personality traits and entrepreneurial traits. In this regard, the shreds of evidence have gathered from the public sector universities of Sindh, which is imparting professional and academic excellence to the lower-middle-class population of the province. Using the Partial Least Squire approach the gathered data was analyzed. The results revealed that Goals and aspirations significantly predicted the entrepreneurial intention among business and commerce graduates. However Big-5 personality and Risk-taking attitude did not influence the entrepreneur's intention. The findings of the study will add value to this existing entrepreneurial literature, in Pakistani particularly the Sindh context.
\end{abstract}

Keywords: Entrepreneurial Intention, Big-5 Personality traits, expectancy-value theory, Sindh, Pakistan.

1..sadia.memon@usindh.edu.pk,

2. javedahmedchandio@hotmail.com,

3.professycom@yahoo.com 


\section{INTRODUCTION}

The mounting unemployment statistics in Pakistan is a greater social problem, which nurtures numerous social issues. In the recent past, Pakistan has been struggling with several haunting social issues, such as terrorism, vast de-investment, shattered confidence of entrepreneurial class, absence of corporate academia liaison. Hence Graduates produced from the existing pattern of education seem to be a futile exercise for the system because they need for the corporate sector and course contents have been in aloof. Accommodating this mushroom of graduates into a job has been a big challenge for the country. The challenge is further soaring as in IMF and World Economic outlook has predicted that the unemployment rate in Pakistan will be 6.140 percent in December 2019, compared to 6.09 percent in the previous year December 2018 (CEIC, 2019). The soaring rate of unemployment is nurturing problems both for the economy and the state. Besides several alternatives to accommodate the unemployed youth to be productive for the economy, the most important alternative suggested by economists is self-employment. Efficient and effective entrepreneurial strategies can be very fruitful both for the economy and the young graduates. Making the graduates realize to become the job producer or job giver instead of becoming employee, far better choice. The choice of entrepreneurship career carries numerous opportunities to grow, to enjoy more benefits, and earn greater financial gains. In order to become a successful entrepreneur, young graduates require attitude and personality. Thus positive attitude and consistent personality have a significant and positive relationship with entrepreneurship intention (Vodă \& Florea, 2019). An accomplishment doesn't mean that how an individual did in his/her schooling or number of academic chronicles he/she possesses. Rather it's the personality and attitude that makes the difference. To excel in any endeavor one may not have to be type "A" person. According to Patel (2017) for the successful execution of entrepreneurial activities, one should have to be street smart rather than book smart. Hence personality traits have a direct and significant impact on entrepreneurial intention, which includes initiating a business, excelling, innovating and expanding entrepreneurial setup (Pekkala, Kerr, \& Xu, 2017).

In order to realize the significance of business attitude among business graduates, this study intended to investigate the relationship between personality traits and entrepreneurial intentions of business graduates in Sindh universities. To inculcate business attitude among young graduates the incubators, accelerators have been established in all public and private business schools in the country. Despite the availability of startup centers in public sector universities of Sindh, but the countable success yet to be documented in the literature (Narula, 2017).

\section{LITERATURE REVIEW}

Entrepreneurs in any economy contribute enormously (Vodă \& Florea 2019). It is an organized, predetermined, deliberate behavior, and its formation heavily depends on personal attitudes. Although extensive literature pertaining to the personality traits and entrepreneurial intention has been documented, however, this study has focused on the big five personality traits model (Costa \& McCrae 1985). Risk 
attitude, Goals and aspiration (Pekkala, Kerr, \& Xu, 2017), by using expectancyvalue theory (Fishbein, 1970), among the business and commerce graduates of public sector university of Sindh. Variables of interest, Big-5 personality traits, Goals and Aspirations and Risk-taking attitude are the predictors of predictand Entrepreneurial intention. Expectancy-value theory describes that students' accomplishments and accomplishment allied options are often evaluated through two factors (Eccles, 1983). They are in business in anticipation to be valued. Expectancy is the degree and extent of confidence an individual has to excel in a given task whereas the task outcome refers to how significant or pleasing its value would be. Both theoretical (Eccles, 1983) and empirical (Nagegast et al., 2011; Trautwein, 2012) studies recommend that anticipations and values intermingle to envisage significant results such as higher-order engagement, commitment, academic excellence and enthusiasm for aspirations and goals

\section{Personality traits and Entrepreneurial intention}

The literature of the early 21 st century has witnessed a significant focus on the intellectual charm by launching business startups. The studies on entrepreneurial personality traits have documented the tremendous amount of empirical pieces of evidence leading to the development of the theoretical framework, having reasonable insights towards improvised policy and business education. The enormous size of literature in this regard intends to seek the answer of fundamental questions: (a) is there any relationship of specific personality trait towards the choice to become entrepreneur, and (b) is there any specific personality trait required to excel and successful execution of any business venture? In an attempt to answer these questions the studies on the relationship between personality traits and entrepreneurial intention have been conducted in the world (Barron, 2004). The scholars have fundamentally inclined during the last decade to the big five-factor personality model (Rauch et al., 2009; Rauch, 2014; Patterson \& Kerrin, 2014; Liu et al., 2019). The extensive literature review conducted by Harvard business school concluded that the studies from 2000 to 2017 focused on big five personality trait models were 10 (Pekkala, Kerr, \& Xu, 2017). The number compared to other personality trait models like the need for autonomy, risk and innovativeness is a bit low. This has necessitated focussing on the big five personality model in this study. the big five personality trait model is consisting of several approaches to define personality, by evaluating openness, conscientiousness, extraversion, agreeableness, and neuroticism. The model has been studied since the 1980s, and has been concluded as significant predictor of career cand work excellence (Ceschi, Costantini, Scalco, Charkhabi, \& Sartori, 2016; Rauch, 2014; John et al., 2008; Costa and McCrae, 1992; Goldberg, 1990; Digman, 1990). Entrepreneurs are predominantly found to be more open to familiarity, express that manager. The scholars have hypothesized such an example in the context of a business venture, an entrepreneur normally remain in habits of volatile business situations and believe in unique, peculiar challenges. Such individuals who strive on challenges and unique conditions are happened to be more innovative, developers of unique business models. Such a personality attitude adds value to excel in a business venture (Pekkala, Kerr, \& Xu, 2017). Besides that higher-order conscientiousness has been observed among entrepreneurs than that of managers (Zhao \& Seibert, 2006). The personality trait extraversion tends to be more active among entrepreneurs because they act as a salesperson of their ideas to 
the investors, clients, customers, therefore they need to be more talkative, energetic, enthusiastic, and ambitious (Zhao \& Seibert, 2006). However, agreeableness and neuroticism have been found less among entrepreneurs than managers. Researchers are of this opinion since almost all the entrepreneurs eventually become the CEOs of their venture, therefore they don't need to be anxious to make others happy, on the other hand, managers (being employees) are required to please their bosses (Pekkala, Kerr, \& Xu, 2017). Entrepreneurs to be less neurotic, due to they need exceptional confidence to go for the risk in initiating a business venture (Zhao \& Seibert, 2006). the role of personality traits towards entrepreneurship as a career choice among students has been studied in various contexts. For example, Israr and Saleem (2018) concluded that entrepreneurial education, agreeableness, extraversion, openness showed a significant and positive relationship with entrepreneurial career intention among Italian students, whereas neuroticism showed a negative relationship in this regard. what is most unique findings of the study conducted on personality traits and entrepreneurial intentions is gender moderates the relationship significantly (Murugesan \& Jayavelu, 2017). Although studies in the Pakistani context have been concluded, a significant number of studies yet to be concluded. Therefore the following hypothesis has been formulated for this study:

\section{H1: Personality traits significantly and positively predicts the entrepreneurial intention among business and commerce graduates}

\section{Goals and Aspiration}

According to the extensive literature review on big five personality traits by Pekkala, Kerr, and Xu, (2017) in Harvard business school, the majority of entrepreneurship researchers use to measure the success of business ventures by having an eye at visible events in the ventures' track record. Such as its survival, its ability to meet the competition and growth. However numerous entrepreneurs, hold very distinct goals and aspirations when initiating and running their businesses, and this attitude will influence several decisions carried out and results experienced. The studies on such issues are, however, unexpectedly very slim. One point which may be discussed a lot is studying to evaluate non-pecuniary inspiration of becoming "you, your own boss" for initiating a business venture. The literature regarding career intention, goals and aspirations to become an entrepreneur is very hard to find in the Asian context. However, scholars round the globe have witnessed to be on their toes to explore the reasons behind starting the business. For example, Hurs and Pugsley (2011) conducted the study and categorized 44 persuasions into five distinct classes: to accumulate income, non-pecuniary rationales, to materialize innovative venture ideas, the dearth of employment opportunities and miscelleniouses. Several studies have identified the non-pecuniary reason behind starting a new business venture. Such categorization may be not standardized, and researches have identified several more motivation typologies. For instance, Kuratko et al. (1997) utilized the fourelement structure of purpose statements explored on the basis of rationales narrated by 234 entrepreneurs: autonomy, intrinsic rewards, extrinsic rewards, and family support. Despite the significance of non-pecuniary reasons for starting business ventures occupy a robust place in business literature. Entrepreneurs motivated by pecuniary $\mathrm{v} / \mathrm{s}$ non-pecuniary rationales usually possess radically unique objective for the companies, they have established. The entrepreneurs motivated by non- 
pecuniary objectives showed meager desire to expand, or innovate their marker position (Hurst \& Pugsley, 2011). Entrepreneurs receive huge non-pecuniary paybacks naturally incline to the business where the scale of output is small such as plumbing, accounting, etc (Hurs \& Pugsley, 2011, 2016). A study focused on the case studies of the fast-growing business ventures, that link the practices and attitudes of originators to their business growth, identified the shift in intention with the passage of time and experience (Bhide, 2000). But in Pakistan reasons are multifarious, five of them are leading reasons (Narula, 2017).

\section{H2: Goals and Aspiration significantly and positively predicts the entrepreneurship intention among students of business and commerce graduates.}

\section{Risk Attitude and Entrepreneurial intention}

Entrepreneurship is the process that originates from idea generation to the brand or the service realization to risk management (Bamber et al., 2002). People having tendencies to become self-employed are often positive towards risk-taking attitudes (Douglas \& Shepherd, 2002). Individuals having the tolerance to bear more risk are happened to be stronger in their quality of decision making autonomy, hence quite capable to become self-employed (Douglas \& Shepherd, 2002). Risk is an amount of uncertainty and probability of sustaining loss attached to the resultants of a business venture (Forlani \& Mullins, 2000; Macko \& Tyszka, 2009; Yurtkoru, 2014). In order to measure the degree of uncertainty and risk attached to the entrepreneurial outcome, the decision-maker often outlines few beliefs regarding the future results Yurtkoru et al, 2014). The quality of the set of beliefs regarding risk-taking attitude depends upon the decision-makers' experience. There are several types of risks often attached to business ventures, which an entrepreneur may bristle with:

\begin{tabular}{|l|l|}
\hline Risk & Explanation \\
\hline Pure Risk & $\begin{array}{l}\text { Type of Risk having a probability of loss of no loss. For instance: A } \\
\text { venture may get affected by fire or not. Such type of risk can be covered } \\
\text { through insurance }\end{array}$ \\
\hline Speculative Risk & $\begin{array}{l}\text { Having the probability of loss or gain. For example, an entrepreneur } \\
\text { may initiate a risk by promoting a fresh business, keeping before the } \\
\text { existing conditions prevailed in the area, which may or may not give } \\
\text { him/her gain }\end{array}$ \\
\hline Fundamental Risk & $\begin{array}{l}\text { Types of risks attached to the venture which, it appeared would be more } \\
\text { devastating and catastrophic. These sorts of risks are often an outcome } \\
\text { of natural, economic, political or social transformations. For example } \\
\text { earthquakes, floods, forex rates volatility, etc. such risk may or may not } \\
\text { be insurable }\end{array}$ \\
\hline
\end{tabular}


IBT Journal of Business Studies (IBT-JBS) Volume 15 Issue 2 December 2019

\begin{tabular}{|l|l|}
\hline Particular Risk & $\begin{array}{l}\text { Such types of risks are often ventured compatible and singled out in lieu } \\
\text { venture, can be overcome while executions of the business plan. For } \\
\text { example safety risks, legal risks, quality risks, etc. }\end{array}$ \\
\hline
\end{tabular}

Source: Project Risk Management, D Van Well-Stam et al., Kogan Page Publications, 2003.

Pakistan is an economy that cannot accommodate every graduate from the universities. Hence researchers have documented various suggestions to the policymakers to develop incubators. In this regard, university regulators in Pakistan (Higher Education Commission) supported its HEIs to develop business incubation centers (HEC.org, 2019). However, the exercise needs more vigorous implementations in sharing success stories. The general perception among the students in Pakistan prevails they are in the academic training to become employees, rather than the employer because after investing their time and money, they don't want to take the risk. Moreover, the track record of business failures in Pakistan is very high (Narula, 2017). In order to measure risk-taking propensity among the students of business and commerce we have formulated the following hypothesis: H3: Risk-taking attitude significantly and positively predicts the entrepreneurial intention as a career choice among students of business and commerce.

\section{Theoretical Framework}

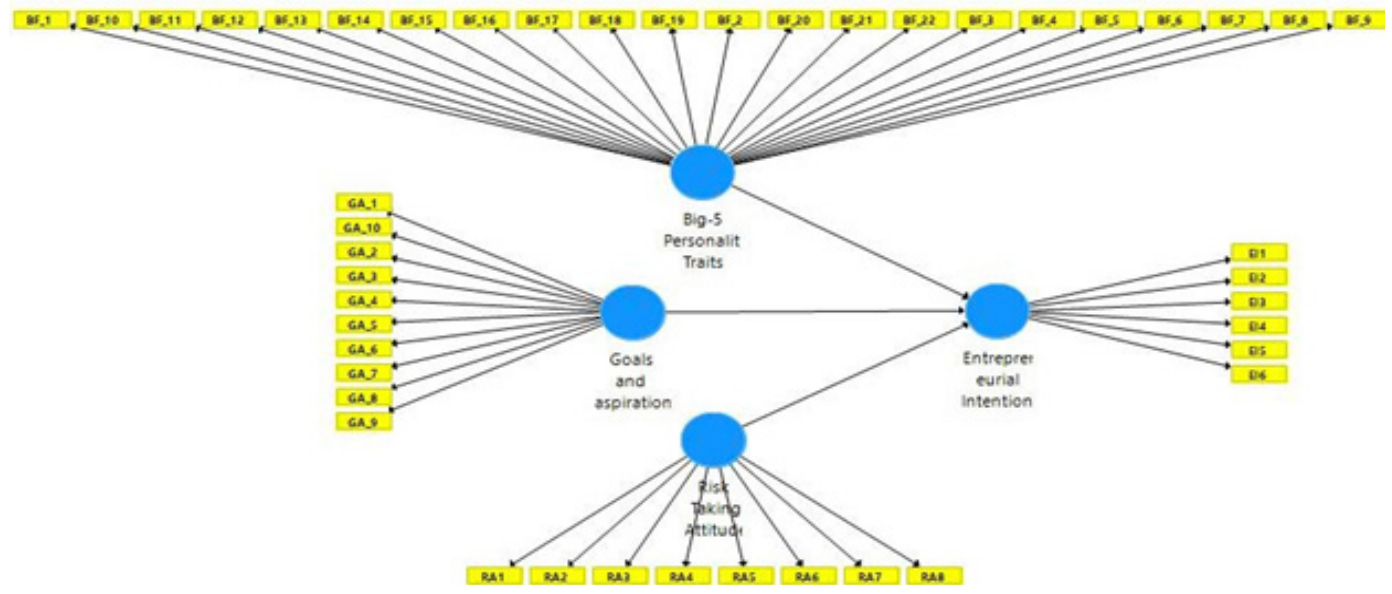

\section{RESEARCH METHODOLOGY}

\section{Sample}

400 business and commerce graduates were randomly targeted from three leading universities of Sindh, 345 questionnaires duly filled were returned back, out of which 300 were useable for analysis. Thus the response rate of the study was 80 percent, 72 percent of the respondents were male and the rest of them were female. The age bracket of the graduates was 20 to 23 years.

\section{Data Collection Instrument}

To measure the entrepreneurial intention among business and commerce graduates we have adopted a predesigned scale of Kolveried (1996). For evaluating the attitude Page | 129 
of goals and aspirations among probable entrepreneurs, we have used the scale of Lazear (2005) for this study. For measuring risk-taking attitude among student the predesigned scale of Atsan (2006) has been used in this study. prior to executing the scale for collecting responses, the necessary modifications were made to suit the contextual need. The expert opinion was sought regarding the modified scale. The data collection instrument contained the demographic part, asking about the gender and age of the respondents.

\section{Data Analysis}

The collected data for the study were analyzed by utilizing a partial least squire approach to SEM. The analysis through PLS has been given in the two-stage process. Namely, estimation of reliability and validity to the measurement model, and path analysis for testing hypotheses of the study. The results for said two approaches have been presented in the upcoming section. The first part presents the outcome of the measurement model (factor analysis); to assess how well the items load on defined latent variables.

\section{Analysis of measurement model}

It was assessed that data collection tools used to conduct the survey for the study were valid and reliable through the measurement model. Hence the internal uniformity among the items, validities (both convergent and discriminant) were assessed. The result (table 2) shows the Cronbach's Alpha reliability, composite reliability (CR), Average variance Extracted (AVE). The reliability for the constructs was ranged from .890 to .920 , which indicates the internal consistency among the indicators were well above the threshold .70. However, the items having out loading less than 0.70 (table 1) were eliminated (Gaskin, 2017). For measuring convergent validity, the AVE has been computed. The output (given in table 2) depicts that all the values range from 0.793 to .966 . This indicates satisfactory convergent validity. In order to measure discriminant validity we have used two approaches to assess the said validity 1,) Fornell Laarcker's (1981) criterion and 2) cross-loading approach. The outcomes of the measurement model confirmed that the discriminant validity was satisfactory.

Table 1 Factor Analysis

\begin{tabular}{|l|l|l|l|l|}
\hline & Big-5 Personality & $\begin{array}{l}\text { Entrepreneurial } \\
\text { Intentions }\end{array}$ & $\begin{array}{l}\text { Goals and } \\
\text { Aspirations }\end{array}$ & $\begin{array}{l}\text { Risk-Taking } \\
\text { Attitude }\end{array}$ \\
\hline BF_1 & 0.989 & & & \\
\hline BF_10 & 0.978 & & & \\
\hline BF_14 & 0.982 & & & \\
\hline BF_2 & 0.951 & & & \\
\hline BF_6 & 0.966 & & & \\
\hline
\end{tabular}


IBT Journal of Business Studies (IBT-JBS) Volume 15 Issue 2 December 2019

\begin{tabular}{|c|c|c|c|c|}
\hline BF_8 & 0.96 & & & \\
\hline EI1 & & 0.994 & & \\
\hline EI3 & & 0.987 & & \\
\hline EI4 & & 0.958 & & \\
\hline EI5 & & 0.992 & & \\
\hline GA_1 & & & 0.968 & \\
\hline GA 2 & & & 0.973 & \\
\hline GA_4 & & & 0.972 & \\
\hline GA 5 & & & 0.863 & \\
\hline RA1 & & & & 0.874 \\
\hline RA2 & & & & 0.892 \\
\hline RA3 & & & & 0.933 \\
\hline RA4 & & & & 0.824 \\
\hline RA5 & & & & 0.953 \\
\hline RA6 & & & & 0.860 \\
\hline
\end{tabular}

Table 2 Reliability and Validity Assessment

\begin{tabular}{|l|c|c|c|c|}
\hline Constructs & $\begin{array}{l}\text { Cronbach's } \\
\text { Alpha }\end{array}$ & rhea & CR & AVE \\
\hline $\begin{array}{l}\text { Entrepreneurial } \\
\text { Intentions }\end{array}$ & 0.900 & 0.992 & 0.991 & 0.966 \\
\hline $\begin{array}{l}\text { Goals and } \\
\text { aspirations }\end{array}$ & 0.920 & 0.973 & 0.971 & 0.893 \\
\hline $\begin{array}{l}\text { Risk Taking } \\
\text { Attitude }\end{array}$ & 0.890 & 0.960 & 0.958 & 0.793 \\
\hline
\end{tabular}

\section{Analysis of Path Model}

Table 3 indicates the outcome results of the hypotheses formulated for this study. The R2 for the model was 0.893 , showing that 89.3 percent variance is explained by Big-5 Personality traits, Goals and Aspiration and Risk-Taking attitude in Page $\mid 131$ 
entrepreneurial intention among business and commerce graduates. The table shows that the only hypothesis $(\mathrm{H} 2)$ is retained. The results show that goals and aspiration $(\beta=0.981, p<0.01)$ was the significant predictor of entrepreneurial intention among business and commerce graduates. The results are also given in the model (Fig 1)

Table 3 Analysis of Path Model

\begin{tabular}{|l|l|l|l|l|}
\hline Hypotheses & Association & Coefficients & T-Value & Supported \\
\hline H1 & $\begin{array}{l}\text { Big-5 Personality traits Entrepreneurial } \\
\text { Intention }\end{array}$ & 0.005 & 0.452 & No \\
\hline H2 & $\begin{array}{l}\text { Goals and Aspiration Entrepreneurial } \\
\text { Intention }\end{array}$ & 0.981 & 114.546 & Yes \\
\hline H3 & $\begin{array}{l}\text { Risk Taking Attitude Entrepreneurial } \\
\text { Intention }\end{array}$ & 0.007 & 0.746 & No \\
\hline R2 $=0.893$ & & & & \\
\hline
\end{tabular}

Fig 1 Structural Model

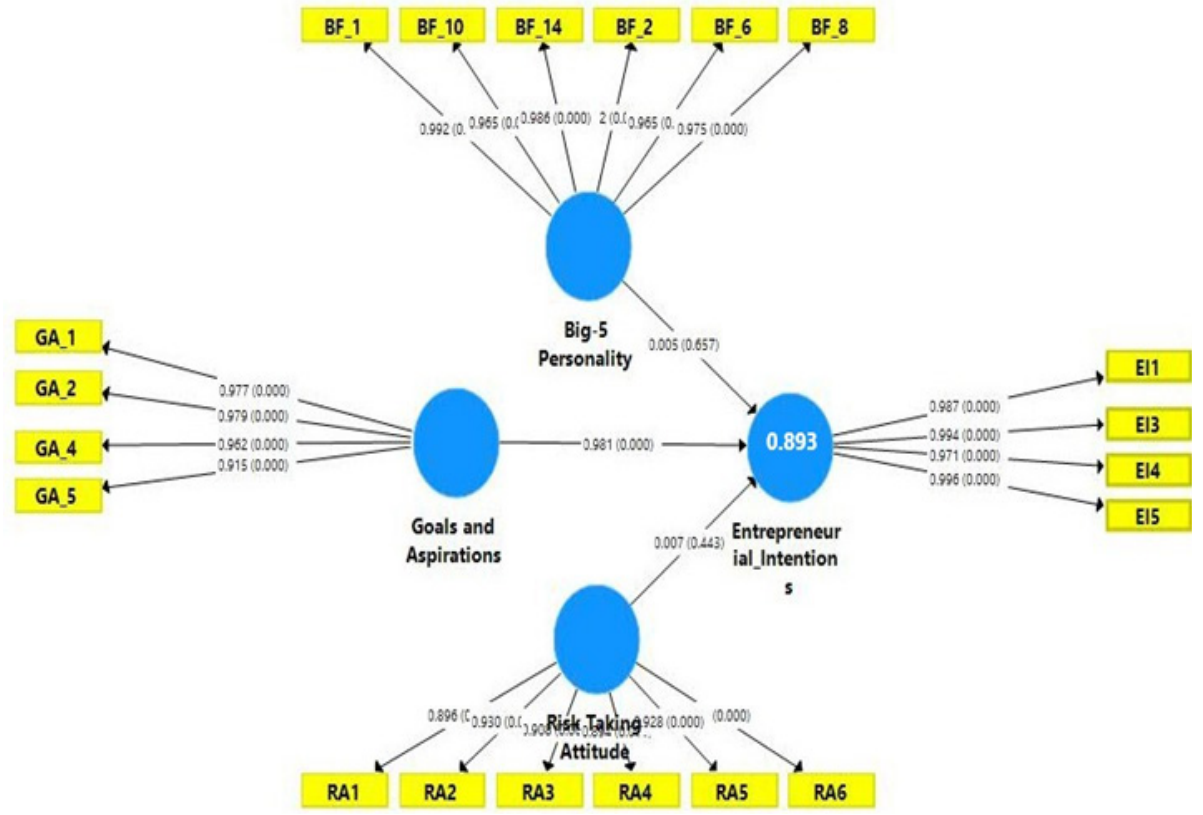

\section{CONCLUSION AND DISCUSSION}

The objective of this research was to analyze the precursors of entrepreneurial intention among business and commerce graduates of public sector universities in Sindh. The expectancy-value theory (Fishbein, 1970) describes that students' accomplishments and accomplishment allied options are often evaluated through 
two factors (Eccles, 1983). They are in business in anticipation to be valued. Expectancy the degree and extent of confidence an individual has to excel in a given task whereas the task outcome refers to how significant or pleasing its value would be. Both theoretical (Eccles, 1983) and empirical (Nagegast et al., 2011; Trautwein, 2012) studies recommend that anticipations and values intermingle to envisage significant results such as higher-order engagement, commitment, academic excellence and enthusiasm for aspirations and goals. As the entrepreneurship has been studied as greater mean economic progress, source of employment, hence it was very much important to evaluate the factors responsible to motivate the business and commerce graduates to become an entrepreneur. The results of this research confirmed that the goals and aspiration is an attitude among the business and commerce graduates causes to become an entrepreneur. However, big 5 personality traits and risk-taking attitude did not predict the entrepreneurial intention among students the results are in line with the outcome of Khan, Rasheed, and Alam (2018). It was authenticated through the extensive literature review the Big 5 personality traits among the people have been a strong predictor of entrepreneurial intention. Besides that family support, friends' encouragement also induces the graduates to become an entrepreneur (Zapkau et al., 2015; Yurtkoru et al., 2014; Altinay et al., 2012; Nanda \& Sorensen, 2006).

The main contribution of this study is an empirical outcome proving that graduates' attitude to become an entrepreneur. The universities and academics particularly the public sector is required to develop the strategy to making the future graduates shift their attitude from becoming subordinate to becoming the boss of their own.

\section{REFERENCES}

Altinay, L., Madanoglu, M., Daniele, \& R. Lashley, C. 2012. The influence of family tradition and psychological traits on entrepreneurial intention, International Journal of Hospitality Management, 31, (2): 489-499

CEIC. (2019, March 12). Pakistan Forecast: Unemployment Rate. Retrieved July 12, 2019, from Census and Economic Information Center Governmental » Economy: https://www.ceicdata.com/en

Ceschi, A., Costantini, A., Scalco, A., Charkhabi, M., \& Sartori, R. (2016). The Relationship Between The Big Five Personality Traits And Job Performance In Business Workers And Employees' Perception. International Journal of Business Research , 16(2),63-76. Resources, Odessa, FL.

Costa, P.T. \& R.R. McCrae. (1992). NEO PI-R Professional Manual. Psychological Assessment

Digman, J.M. (1990). Personality structure: Emergence of the five-factor model. Annual Review of Psychology, 41(1), 417-440.

Eccles, J. (1983). Expectancies, values, and academic behaviors. In J. T. Spence (Ed.), Achievement and achievement motives: Psychological and sociological approaches (pp. 75-146). San Francisco, CA: W. H. Freeman.

Fishbein, M., \& Ajzen, I. (1975). "Belief, Attitude, Intention, and Behavior: An Introduction to Theory and Research". Reading, MA: Addison-Wesley.

Goldberg, L.R. (1990). An alternative "description of personality": The Big-Five factor structure. Journal of Personality and Social Psychology, 59(6), 1216-

Page $\mid 133$ 


\section{9}

Israr, Muhammad; Saleem, Mazhar (2018). Entrepreneurial intentions among university students in Italy, Journal of Global Entrepreneurship Research,8(20),1-14, http://dx.doi.org/10.1186/s40497-018-0107-5

John, O. P., \& Srivastava, S. (1999). The Big-Five trait taxonomy: History, measurement, and theoretical perspectives. In L. A. Pervin \& O. P. John (Eds.), Handbook of personality: Theory and research (Vol. 2, pp. 102-138). New York: Guilford Press

John, O.P., L.P. Naumann \& C.J. Soto. (2008). The paradigm shift to the integrative big five trait taxonomy: history, measurement, and conceptual issues. In O.P. John, R.W. Robins \& L.A. Pervin (Eds.). Handbook of Personality: Theory and Research. Guilford Press, New York, 114-158.

Kerr, S. P., Kerr, W., \& Xu, T. (2017). Personality Traits of Entrepreneurs: A Review of Recent Literature.

Murugesan, R., \& Jayavelu, R. (2017). The Influence of Big Five Personality Traits and Self-efficacy on Entrepreneurial Intention: The Role of Gender. Journal of Entrepreneurship and Innovation in Emerging Economies, 3(1), 41-61. doi: $10.1177 / 2393957516684569$

Nanda, R. \& Sorensen, J., 2009. Workplace Peers and Entrepreneurship (March 10, 2009). Harvard Business School Entrepreneurial Management, Working Paper No. 08-051.

Narula, T. T. (2017, August 25). Five reasons why startups fail. Karachi, Sindh, Pakistan.

Pekkala, S. K., Kerr, W. R., \& Xu, T. (2017). Personality Traits of Entrepreneurs:A Review of Recent Literature. Harvard Business School Working Paper, 1-50.

Patterson, F. \& M. Kerrin. (2014). Characteristics and behaviors associated with innovative people in small and medium-sized enterprises. In E. Chell \& M. Karatas-Ozkan (Eds.) Handbook of Research on Small Business and Entrepreneurship. Edward Elgar, London, UK, 187-206.

Rauch, A. (2014). Predictions of entrepreneurial behavior: A personality approach. In E. Chell \& M. Karatas-Ozkan (Eds.) Handbook of Research on Small Business and Entrepreneurship. Edward Elgar, London, UK, 165-183.

Rauch, A., J. Wiklund, G.T. Lumpkin \& M. Frese. (2009). Entrepreneurial orientation and business performance: An assessment of past research and suggestions for the future. Entrepreneurship Theory and Practice, 33, 761-787

Vodă, A., \& c, N. (2019). Impact of Personality Traits and Entrepreneurship Education on Entrepreneurial Intentions of Business and Engineering Students. Sustainability, 11(4), 1192.

Yurtkoru, S. Kuşcu, Z.K., \& Doğanay, A. 2014. Exploring the Antecedents of Entrepreneurial Intention on Turkish University Students, Procedia - Social and Behavioral Sciences, 150: 841-850

Zhao, H. \& S.E. Seibert. (2006). The big five personality dimensions and entrepreneurial status: A meta analytical review. Journal of Applied Psychology, 91, 259-271.

Zapkau, F.B., Schwens, C., Steinmetz, H., \& Kabst, R. 2015. Disentangling the effect of prior entrepreneurial exposure on entrepreneurial intention, Journal of Business Research, 68,(3): 639-653. 